\title{
Our Commitment to Quality
}

Philip Machanick sacj.editor@gmail.com

Rhodes University, Grahamstown

\section{Introduction}

One of the problems of a relatively small regional journal is being visible over the noise of the growing cottage industry in predatory open access publications, some charging as little as US\$50 to publish a paper with minimal to no review.

$S A C J$ maintains standards by a combination of approaches:

- rigorous review - we apply standards that any reasonable general-readership journal applies

- plagiarism checks - we check each submission before review for similarity to published work and do not send papers out for review if they fail to meet a reasonable standard for originality

- indexing - we are indexed on Scopus as of 2016, as well as being possible to find via the DOI database maintained by Crossref and the Directory of Open Access Journals (DOAJ)

In this editorial, I expand briefly on how we are working on enhancing visibility and how authors can help with this. I end with a summary of papers in this issue.

I would like to welcome Machdel Matthee as an additional Information Systems editor. We now have five associate editors, reflecting a growing number of submissions.

\section{Visibility}

Some ways of achieving visibility are easier than others. DOAJ, for example, does not do quality checks on journals so, while it is useful to be visible there, that is not an indicator to potential readers of the quality of a journal. Similarly, issuing DOIs (through Crossref) means that you can find a paper published in $S A C J$ via another route. An increasing number of metadata aggregators are using Crossref as a starting point for searches. Valuable though that is, simply issuing a DOI is not a measure of quality, since any publisher can sign up for this service.

How can you make a difference? If you cite work published in $S A C J$ in widely read journals and conferences, that increases visibility. You can also target SACJ for work that is likely to be

Machanick, P. (2016). Our Commitment to Quality [Editorial]. South African Computer Journal 28(2), vii-viii. https: //doi.org/10.18489/sacj.v28i2.441

Copyright (C) the author(s); published under a Creative Commons NonCommercial 4.0 License (CC BY-NC 4.0).

$S A C J$ is a publication of the South African Institute of Computer Scientists and Information Technologists. ISSN 1015-7999 (print) ISSN 2313-7835 (online). 
widely read. Our most cited paper (van den Bergh \& Engelbrecht, 2000), with over 300 citations on Google Scholar, was by an author who has subsequently published a paper (van den Bergh \& Engelbrecht, 2004), with over 1000 citations, and has been awarded an 'A' rating by the National Research Foundation in 2014. So publishing in SACJ can lead to good things.

Help us grow $S A C J$ : send us good papers, volunteer to review and propose special issues.

\section{In this Issue}

This issue contains two research papers, a viewpoint paper and a letter to the editor.

Kroeze and Malan in "User Authentication based on Continuous Touch Biometrics" show that measurement of touch-based interaction is sufficient to distinguish between users.

Padayachee uses design science and the Delphi technique in "Internet-Mediated Research: Challenges and Issues" to explore the how response rates and the demographics of experts are related.

In his viewpoint, "Digital Forensic Science: A Manifesto", Olivier makes a case for digital forensic science to learn from experiences and mistakes of older branches of forensic science.

Gruner's letter reports on the SACLA '16 conference and its move to publishing proceedings in Springer's CCIS series.

\section{Looking Ahead}

2016 has been a difficult year for South African academia, characterised by angry protests. That may have slowed research outputs. The SACJ editorial team hopes 2017 goes better.

For next year, we have extended papers from a previous SAICSIT conference under review and a call for papers for a special issue on ICT in Education.

We look forward to author submissions for the special issue as well as for general issues.

\section{References}

van den Bergh, F. \& Engelbrecht, A. P. (2000). Cooperative learning in neural networks using particle swarm optimizers. South African Computer Journal, (26), 84-90.

van den Bergh, F. \& Engelbrecht, A. P. (2004). A cooperative approach to particle swarm optimization. IEEE Transactions on Evolutionary Computation, 8(3), 225-239. 